\title{
Detection errors in a task with articulatory suppression: Phonological recoding and reading
}

\author{
HELEN B. GOLDMAN and ALICE F. HEALY \\ University of Colorado, Boulder, Colorado
}

\begin{abstract}
In two experiments, subjects read passages of text and circled instances of a target letter under normal conditions or while engaged in articulatory suppression. In Experiment 1, subjects searching for the letter e made a disproportionately large number of errors on the word "the" and more errors when e occurred in unstressed than in stressed syllables of three-syllable words. In Experiment 2, subjects searching for the letter $f$ made an exceedingly large number of errors on the word "of." Articulatory suppression significantly reduced the stress effect in the three-syllable words but did not reduce the tendency to make errors on "the" or "of," suggesting that phonological recoding is responsible for this effect of stress but does not influence the unitization processes of reading.
\end{abstract}

In a study published in 1966, D. W. J. Corcoran noticed that subjects made an inordinate number of errors in detecting specific letters in the frequent and familiar word "the." Although Corcoran explained this finding by proposing that subjects skip over the word "the" because of its syntactic and semantic redundancy, Healy (1976) proposed that this finding was due to unitization. She hypothesized that readers tend to employ the largest reading units available to them. In familiar, highfrequency words, these units are presumably larger than single letters, and might, in fact, be the entire word. Therefore, subelements of these familiar word units, that is, letters, would be likely to be missed in a letter detection task. Healy's experiments supported this hypothesis; she found a bias toward errors in familiar versus unfamiliar words, even when syntactic and semantic redundancy was eliminated because only nouns, not function words, were used, and these words were scrambled in the text.

Healy and Drewnowski (1983) extended this investigation and refined the unitization model in an experiment in which they showed that letter detection improved dramatically when test words were misspelled. It was clear that these words were being scanned, not skipped over, or else the misspellings would not have drawn the readers' attention to more of the target letters. Drawing on the interactive reading model proposed by McClelland and Rumelhart (1981) and the earlier work on automatic processing by LaBerge and Samuels (1974) and others, Healy and Drewnowski proposed that written text is processed in a parallel fashion at all levels that are available to the reader. Thus, processing may be occurring

The research reported here was supported in part by NSF Grant BNS80-25020 to the Institute of Cognitive Science at the University of Colorado. Boulder. Requests for reprints should be addressed to Alice F. Healy, Department of Psychology, University of Colorado, Campus Box 345. Boulder. CO 80309. simultaneously at the levels of letters, syllables, words, and phrases. Familiarity would be an aid in processing at any given level, so we could expect, for example, that common words would be processed at the word level more easily than rare words. If the word being processed was identified at the word level before the smaller units, such as letters, were fully processed, full processing of these units would not be completed. For this reason, subjects tended to miss many target letters in familiar words; they were often able to identify a familiar word without identifying all of its component letters, and they proceeded to the next portion of the text without completing the processing at the letter level.

One issue noted by Healy and Drewnowski (1983), which their studies raised but did not fully resolve, was whether the larger reading units being studied in their experiments were purely visual perceptual units, or instead involved the subjects' subvocalized responses. In other words, were the readers identifying visual patterns, or were they scanning a memory representation consisting of a phonologically recoded response to the original visual image of the text and identifying phonetic patterns?

There is considerable evidence that speed and other measures of performance on visual perception tasks are influenced by factors that can be localized at nonperceptual, or response, levels of processing. Such evidence comes from a variety of research paradigms, such as Krueger's (1970) studies on the effect of acoustic confusability in visual search (see McCusker, Hillinger, \& Bias, 1981, for a review of related studies). The possibility exists that more than visual pattern recognition may be involved in the unitization of reading elements.

To expand the investigation of the nature of reading units, Drewnowski and Healy (1982) examined phonetic factors. Specifically, they studied another finding reported by Corcoran (1966) - that subjects missed more instances of the target letter e when the e occurred within a word in which it is silent (as in the word "take") than when 
it occurred within a word in which it is pronounced (as in the word "elephant"). When Drewnowski and Healy controlled for such factors as word frequency and location of the target letter within the word, they found that phoneme voicing did not affect letter detection. However, they also found that for common three-syllable words, syllable stress, at least on the second and third syllables, did affect letter detection performance. Subjects made more errors on unstressed es than on stressed es in the latter parts of the words. Along similar lines, a more recent study by Read (1983) pointed to evidence that subjects' poor detection performance on the word "of" was due to the uncommon pronunciation of the target letter $f$ in that word.

In order to determine whether there is some involvement of phonological recoding in the unitization of reading elements, to establish that the stress effect is indeed due to phonetic factors, and to verify that Read's (1983) effects are truly attributable to pronunciation, we designed the present experiments to impede the normal phonological recoding that takes place during reading. It seems reasonable to assume that if subjects were to repeat a word aloud as they performed a reading and letter detection task, it would be difficult for them to respond with a phonological recoding of what they were reading. Articulatory suppression has been used successfully to disrupt the normal processes of phonological recoding in many experiments on short-term memory and reading (see, e.g., Estes, 1973; Healy, 1975; Healy \& Nairne, 1985; Levy, 1971, 1978; Murray, 1967; Tell, 1971). Use of articulatory suppression in the present context should shed light on the role of phonological recoding in the unitization process previously outlined. If the phenomenon of unitization were to break down so that readers increased processing at the single-letter level during articulatory suppression, then subjects would improve letter detection in familiar words and approach their performance with less familiar words, just as Drewnowski and Healy (1982) found, for example, that subjects improved letter detection in common words when the familiar configuration was disturbed by printing the words with alternating upper- and lowercase letters. This improvement would point to the conclusion that phonological recoding is involved in the unitization process. Likewise, if either the stress effect (Drewnowski \& Healy, 1982 ) or the pronunciation effect (Read, 1983) were to be reduced during articulatory suppression, then phonological recoding would be plausible as the locus of that effect. In summary, manipulation of the reading process by use of articulatory suppression should shed light on the role of phonological recoding in reading and its influence on the detection of letters in printed text.

\section{EXPERIMENT 1}

Experiment 1 was designed to establish that articulatory suppression is a valid technique for exploring what effects are due to phonological recoding. We used the original three-syllable words in which the stress effect was found (Drewnowski \& Healy, 1982), in order to see if, in fact, articulatory suppression would depress or destroy the effect. To determine whether the stress effect and any effects of articulatory suppression on the stress effect were generalizable to other words, we included a new set of two-syllable words. Furthermore, to determine whether the phenomenon of unitization is due in some part to phonological recoding, we examined the effect of articulatory suppression on the word "the," which has been found to exhibit strong evidence for unitization.

\section{Method}

Subjects. Forty-eight students from the University of Colorado participated for partial credit in an introductory psychology course. All students were native speakers of English.

Design and materials. A 220-word passage of connected text, in the style of a newspaper editorial, was constructed for the experiment. The passage contained 138 es in all, 56 of which were in test words. No test word contained more than one e. The passage was margined and indented differently in two versions, so that test words fell in different positions on the page. The passage began with an indentation in one version and without an indentation in the other; the former version had a left margin of 0 and a right margin of 78, the latter version a left margin of 0 and a right margin of 80 (out of a possible 80-character spread). The result of these variations was that no two- or three-syllable test word was ever in the first or last position on a line in both versions of the text.

The test words fell into three categories.

Three-syllable words. We used 16 relatively high-frequency threesyllable words that had previously been used by Drewnowski and Healy (1982, Experiment 3). These words were used to replicate the stress effect that was found in frequent words with $\mathrm{e}$ in the middle or last syllable. In the earlier study, unstressed es in these words had elicited significantly more detection errors than did stressed es. The mean frequency of these words in a $1,014,232$-word corpus was 95.8 for the words with unstressed es and 63.3 for the words with stressed es (Kučera and Francis, 1967). These 16 words fell into four subgroups of 4 words each: words with stressed es in the middle syllable, words with unstressed es in the middle syllable, words with stressed es in the last syllable, and words with unstressed es in the last syllable. The specific words employed are listed in Table 1.

Two-syllable words. We used 10 pairs (20 words) of relatively high-frequency two-syllable words containing an $e$ in the second syllable. The words had identical final letter patterns, but opposite stress patterns (e.g., "forget" and "market"). The mean frequency for the words with stressed es was 60.0 and that for the words with unstressed es was 62.5 (Kučera \& Francis, 1967). The words varied in length from 5 to 7 letters, with no pair members differing from one another in length by more than one letter. Mean word length was 5.8 letters for the stressed-e words and 6.1 letters for the unstressed-e words. The words selected had no affixes. This was the primary reason for using two-syllable words, as the likelihood

Table 1 List of Three-Syllable Words

\begin{tabular}{|c|c|c|c|}
\hline \multicolumn{4}{|c|}{ Target Location } \\
\hline \multicolumn{2}{|c|}{ Syllable 2} & \multicolumn{2}{|c|}{ Syllable 3} \\
\hline Stressed & Unstressed & Stressed & Unstressed \\
\hline $\begin{array}{l}\text { attention } \\
\text { directly } \\
\text { successful } \\
\text { professor }\end{array}$ & $\begin{array}{l}\text { suddenly } \\
\text { properly } \\
\text { governor } \\
\text { powerful }\end{array}$ & $\begin{array}{l}\text { incorrect } \\
\text { discontent } \\
\text { introspect } \\
\text { indirect }\end{array}$ & $\begin{array}{l}\text { consider } \\
\text { character } \\
\text { apartment } \\
\text { citizens }\end{array}$ \\
\hline
\end{tabular}


Table 2

List of Two-Syllable Word Pairs

\begin{tabular}{lll} 
& \multicolumn{2}{c}{ Second Syllable } \\
\hline Stressed & Unstressed \\
\hline concern & pattern \\
forget & market \\
hotel & travel \\
correct & insect \\
alert & concert \\
direct & aspect \\
suggest & forest \\
collect & prospect \\
intent & silent \\
motel & novel \\
\hline
\end{tabular}

of prefixes and suffixes increases with word length. The particular words used are given in Table 2.

"The."The 56 test words included 20 instances of the word "the."

Procedure. The subjects were tested individually in a quiet room. Each subject read a single version of the passage twice, once in the normal condition and once in the suppression condition. Passage version and condition order were counterbalanced across subjects. The subjects were instructed to read the passage to themselves at their normal reading speed and in their normal manner and to circle each instance of the target e. For the suppression condition, subjects were also told to repeat aloud the word "psychology" as they performed the task. All subjects were also told that if they ever realized they had missed a target in a previous word, they should not backtrack to circle it. The texts and directions had been typed doublespaced with a computer dot-matrix printer, dittoed, and then stapled together into a booklet for each subject. Copies of the passages and directions were preceded by a consent form. Subjects read the directions and turned to each passage after being instructed to do so by the experimenter.

\section{Results and Discussion}

Three-syllable words. The results for the three-syllable words are summarized in Table 3 in terms of error percentages as a function of condition order, condition (normal, suppression), position of the syllable containing the target (second, third), and whether or not that syllable is stressed.

For these three-syllable words, used previously by Drenwnowski and Healy (1982, Experiment 3), there was no significant difference between the suppression (13.5\% errors) and normal $(12.1 \%)$ conditions on the average $[\mathrm{F}(1,46)<1]$, but there was a significant interaction between suppression condition and condition order $[F(1,46)$ $=4.0, \mathrm{MSe}=341, \mathrm{p}=.048]$. Specifically, subjects

Table 3

Error Percentages in Experiment 1 on Three-Syllable Words as a Function of Condition Order, Condition, Syllable Position, and Syllable Stress

Syllable Position

\begin{tabular}{|c|c|c|c|c|}
\hline \multirow[b]{3}{*}{ Condition } & \multicolumn{4}{|c|}{ 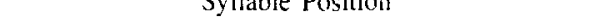 } \\
\hline & \multicolumn{2}{|c|}{ Second } & \multicolumn{2}{|c|}{ Third } \\
\hline & Stressed & Unstressed & Stressed & Unstressed \\
\hline \multicolumn{5}{|c|}{ Normal First } \\
\hline Normal & 7.3 & 10.4 & 6.2 & 20.8 \\
\hline Suppression & 11.5 & 8.3 & 7.3 & 8.3 \\
\hline \multicolumn{5}{|c|}{ Suppression First } \\
\hline Normal & 8.3 & 18.8 & 9.4 & 15.6 \\
\hline Suppression & 10.4 & 26.0 & 20.8 & 15.6 \\
\hline
\end{tabular}

given the normal condition first made more errors on the normal $(11.2 \%)$ than on the suppression $(8.9 \%)$ condition, but subjects given suppression first showed the opposite pattern (suppression, $18.2 \%$; normal, $13.0 \%$ ), suggesting a facilitative effect of practice. An alternative way to view this interaction is in terms of a passage familiarization or repetition effect (see, e.g., Levy, 1983), rather than a practice effect. The first reading of the passage produced more errors than the second for the suppression condition (first, $18.2 \%$; second, $8.9 \%$ ) but not for the normal condition (first, $11.2 \%$; second, $13.0 \%$ ), suggesting that there is a facilitatory passage repetition effect only when the first reading of the passage is done normally.

More importantly, an overall stress effect was again detected, as it was in the original experiment by Drewnowski and Healy $(1982)[\mathrm{F}(1,46)=12.3, \mathrm{MSe}=223$, $p=.001]$. More errors were made on words with $\mathrm{e}$ in the unstressed syllable (15.5\%) than on those with $e$ in the stressed syllable (10.2\%). There was also a three-way interaction of stress, position of the syllable containing $\mathrm{e}$, and condition order $[\mathrm{F}(1,46)=10.4, \mathrm{MSe}=237$, $p=.003]$. For subjects given the normal condition first, the stress effect was due to es in the third syllable, but for subjects given the suppression condition first, the stress effect was due to es in the second syllable (see Table 3).

Most crucially, a two-way interaction of stress and suppression condition showed, as expected, that the difference between stressed and unstressed es was larger in the normal condition (stressed, $7.8 \%$; unstressed, $16.4 \%$ ) than in the suppression condition (stressed, $12.5 \%$; unstressed. $14.6 \%)[\mathrm{F}(1,46)=4.7, \mathrm{MSe}=218, \mathrm{p}=$ $.034]$. A three-way interaction of stress, suppression condition, and position of the syllable containing the $\mathrm{e}$ $[\mathrm{F}(1,46)=4.9, \mathrm{MSe}=177, \mathrm{p}=.031]$ indicated that the position of the es affected the results as follows: Suppression reversed the stress effect most drastically in words having the $\mathrm{e}$ in the third syllable (see Table 3). An analysis done only on the first reading of the passage (to remove any effects of practice or passage repetition) also yielded a significant main effect of stress $[\mathrm{F}(1,46)=12.3$, MSe $=193, p=.001]$ and a significant three-way interaction of stress, suppression condition, and target syllable position $[\mathrm{F}(1,46)=15.5, \mathrm{MSe}=201, \mathrm{p}<.001]$.

Two-syllable words. The results for the two-syllable words are summarized in Table 4 in terms of error percentages as a function of condition order, condition, and syllable stress.

For the two-syllable words in the passage, there were significantly more errors with suppression $(13.3 \%)$ than under normal conditions $(9.2 \%)[\mathrm{F}(1,46)=8.4$, MSe $=$ $100, \mathrm{p}=.006]$. Furthermore, there was a significant interaction between suppression condition and condition $\operatorname{order}[\mathrm{F}(1,46)=5.4, \mathrm{MSe}=100, \mathrm{p}=.024]$. The disruptive effect of suppression was larger when suppression was the first condition (suppression, $17.7 \%$; normal, $10.2 \%$ ) than when it was the second condition (suppression, $9.0 \%$; normal, $8.1 \%$ ), suggesting that the facilitative effect of practice on letter detection counteracted the dis- 
Table 4

Error Percentages in Experiment 1 on Two-Syllable Words as a Function of Condition Order, Condition, and Syllable Stress

\begin{tabular}{lccccc}
\hline & \multicolumn{4}{c}{ Condition } \\
\cline { 2 - 3 } Condition Order & \multicolumn{2}{c}{ Normal } & & \multicolumn{2}{c}{ Suppression } \\
\cline { 2 - 3 } \cline { 5 - 6 } & Stressed & Unstressed & & Stressed & Unstressed \\
\hline Normal First & 5.8 & 10.4 & & 7.5 & 10.4 \\
Suppression First & 10.8 & 9.6 & & 17.1 & 18.3 \\
\hline
\end{tabular}

ruptive effect of suppression to some extent. In terms of passage repetition, as with the three-syllable words, the first reading of the passage produced more detection errors than did the second for the suppression condition (first, 17.7\% ; second, 9.0\%), but not for the normal condition (first, $8.1 \%$; second, $10.2 \%$ ), suggesting that a previous normal reading, but not a previous reading with suppression, facilitates letter detection.

In test words of two syllables, words with unstressed es had marginally significantly more errors $(12.2 \%)$ than words with stressed es $(10.3 \%)[F(1,46)=2.9$, MSe $=59, \mathrm{p}=.094 \mathrm{]}$. A marginally significant interaction of stress with condition order $[\mathrm{F}(1,46)=2.9, \mathrm{MSe}=59$, $\mathbf{p}=.094]$ was due to the fact that the difference in errors occurred only when normal was the first condition (stressed, 6.7\% ; unstressed, 10.4\%), and not when suppression was first (stressed and unstressed $=14.0 \%$ ). An analysis conducted on the data from the first reading of the passage yielded only a significant effect of suppression condition $[\mathrm{F}(1,46)=4.5, \mathrm{MSe}=495, \mathrm{p}=.038]$, but the difference between detection errors on the words with stressed targets $(11.5 \%)$ and unstressed targets $(14.4 \%)$ was not statistically reliable $[\mathrm{F}(1,46)=2.5$, MSe $=81, \mathrm{p}=.116]$.

Most critically, in the two-syllable words, suppression had no significant effect on the pattern of errors for stressed and unstressed es (see Table 4); there was no interaction between stress and suppression condition in either the analysis including both readings of the passage or the analysis including only the first reading [in each case, $F(1,46)<1]$. This negative result suggests that the marginal effect of stress that was evident for the twosyllable words may not be due to phonological recoding.

"The." The results for the word "the" are summarized in Table 5 in terms of error percentages as a function of condition order and condition.

The overall percentage of errors on "the" was very high $(60.9 \%)$, in accord with the findings from earlier studies (e.g., Healy, 1976). On the word "the," which has previously been shown to produce the most dramatic evidence for the unitization hypothesis, there were significantly more errors during the suppression condition $(64.1 \%)$ than during the normal condition $(57.7 \%)$ $[\mathrm{F}(1,46)=4.7, \mathrm{MSe}=204, \mathrm{p}=.032]$. When only the first reading of the passage was considered, the error rate on the suppression condition (70.8\%) was still higher than that on the normal condition $(60.4 \%)$, but the effect of suppression was not statistically reliable $[F(1,46)=1.6$, $\mathrm{MSe}=830, \mathrm{p}=.214]$. These findings indicate that verbal suppression does not facilitate detection of individual letters, as it would if it interfered with the unitization process. If phonological recoding were involved in the formation of multiletter units, subjects should do better at detecting individual letters when such recoding is disrupted, but, in fact, they did worse. There was a significant interaction between the order of conditions and the conditions themselves $[\mathrm{F}(1,46)=10.6, \mathrm{MSe}=204$, $p=.002]$. The disruptive suppression effect was evident when suppression was the first condition presented, but not when it was the second condition (see Table 5). Apparently, the practice derived from the first reading counteracted the suppression effect. In terms of passage repetition, for the word "the," unlike the two- and three-syllable words, there were more detection errors on the first reading of the passage for both the normal condition (first, $60.4 \%$; second, $55.0 \%$ ) and the suppression condition (first, $70.8 \%$; second, $57.3 \%$ ).

Although suppression did not significantly decrease detection errors on the word "the," as would be expected if the errors were due to subjects' searching for target letters through a phonological memory representation of the text, suppression did significantly increase error rate on "the," as it did on the two-syllable words. These increases may be attributable to a reduction in general processing capacity due to the demands of the concurrent task (see, e.g., Waters, Komoda, \& Arbuckle, 1985). However, such a general processing decrement cannot be used to explain the effects of articulatory suppression on the detection of targets in three-syllable words. In that case, suppression eliminated the effect of stress but did not lead to an overall increase in errors.

The finding that the error rate on "the" is increased, not decreased, by suppression is particularly important because, as mentioned earlier, other manipulations that impede reading have been found to have an enhancing effect on detection. Subjects make fewer letter detection errors when the text is typed in alternating upper- and lowercase characters or when the test words are misspelled (e.g., Drewnowski \& Healy, 1982; Healy \& Drewnowski, 1983). These findings provide evidence for the existence of multiletter units of a visual nature. The consistently large number of letter detection errors on the word "the" may be due to the fact that the letters of that common word form a familiar visual configuration that can be identified before identification of the component letters is complete. Accordingly, manipulations that cause a disruption of the familiar multiletter visual patterns should

Table 5

Error Percentages in Experiment 1 on "the" as a Function of Condition Order and Condition

Condition

\begin{tabular}{lcc}
\cline { 2 - 3 } Condition Order & Normal & Suppression \\
\hline Normal First & 60.4 & 57.3 \\
Suppression First & 55.0 & 70.8
\end{tabular}


lower error rates in the letter detection task. Misspelling and alternating letter case clearly disturb normal word configuration, but articulatory suppression should have no effect on visual pattern recognition.

\section{EXPERIMENT 2}

In order to assess Read's (1983) hypothesis that atypical pronunciation may account for exceedingly poor performance in detecting the letter $\mathrm{f}$ in the word "of," the same sentence he used was presented to subjects in this experiment.

\section{Method}

Subjects. The 48 subjects were those who participated in Experiment 1 .

Design and materials. A single sentence was employed in this study, the same sentence used by Read (1983): "Finished files are the result of years of scientific study combined with the experience of years." This sentence was typed on its own page in the test booklet; directions were on the previous page.

Procedure. Subjects performed each condition of this experiment directly after the corresponding condition of Experiment 1 . The procedure was the same as in Experiment 1 except that the target was changed to $f$. The order of conditions, normal and suppression, was thus the same for a given subject as in Experiment 1 .

\section{Results and Discussion}

The results are summarized in Table 6 in terms of error percentages as a function of condition order, condition, and test word type ("of," other words).

In the "finished files" passage, the extremely large error rate for $f$ in "of" $(93.8 \%)$, as opposed to other test words $(6.5 \%)$, was highly significant $[F(1,46)=891.9$, $\mathrm{MSe}=410, \mathrm{p}<.001]$, as was found in Read's (1983) work. As with the word "the" and the two-syllable words containing e, there were more errors in the suppression condition $(52.1 \%)$ than in the normal condition $(48.3 \%)$ $[\mathrm{F}(1,46)=9.0, \mathrm{MSe}=76, \mathrm{p}=.005]$. Suppression increased error rate more on other words (suppression, 9.6\%; normal, 3.4\%) than on "of" (suppression, $94.5 \%$; normal, 93.1\%) $[\mathrm{F}(1,46)=4.1, \mathrm{MSe}=68, \mathrm{p}=.045]$. This interaction can be attributed in part, however, to a ceiling effect on errors. In an analysis restricted to the first reading of the passage, there was a significant difference between errors on "of" $(94.5 \%)$ and on other test words $(9.0 \%) \quad[\mathrm{F}(1,46)=688.3, \mathrm{MSe}=255, \mathrm{p}<$ $.001 \mathrm{~J}$, and between the normal condition (45.9\%) and the suppression condition $(57.6 \%)[\mathrm{F}(1,46)=13.5, \mathrm{MSe}=$ $245, \mathrm{p}<.001]$, but the interaction between test word

Table 6

Error Percentages in Experiment 2 on "of" and Other Words as a Function of Condition Order and Condition

\begin{tabular}{|c|c|c|c|c|}
\hline \multirow[b]{3}{*}{ Condition Order } & \multicolumn{4}{|c|}{ Test Word Type } \\
\hline & \multicolumn{2}{|c|}{ "of" } & \multicolumn{2}{|c|}{ Other Words } \\
\hline & Normal & Suppression & Normal & Suppression \\
\hline Normal First & 90.3 & 90.3 & 1.4 & 2.8 \\
\hline Suppression First & 95.9 & 98.6 & 5.5 & 16.5 \\
\hline
\end{tabular}

type and suppression condition was not significant $[\mathrm{F}(1,46)=1.1, \mathrm{MSe}=255, \mathrm{p}=.297]$. In any event, the error rate on the word "of" did not decline with articulatory suppression, which suggests that phonological recoding contributed to this effect in only a minor way, if at all.

Subjects performed significantly better overall when the normal condition was first $(46.2 \%)$ than when the suppression condition was first $(54.1 \%)[\mathrm{F}(1,46)=6.8$, $\mathrm{MSe}=444, \mathrm{p}=.012]$. A significant two-way interaction of condition order and the conditions themselves $[F(1,46)=6.1, \mathrm{MSe}=76, \mathrm{p}=.016]$ showed that the disrupting influence of suppression was smaller when it was the second condition (suppression, $46.5 \%$; normal, $45.9 \%$ ) than when it was the first condition (suppression, $57.6 \%$; normal, $50.7 \%$ ), presumably because of a counteracting facilitation by practice from the first reading, as was found in Experiment 1. As for the two- and threesyllable words in Experiment 1, the first reading of the passage yielded more errors than the second for the suppression condition (first, $57.6 \%$; second, $46.5 \%$ ) but not for the normal condition (first, $45.9 \%$; second, $50.7 \%$ ), suggesting a facilitative effect of a prior normal reading but not a facilitative effect of a prior reading under articulatory suppression.

\section{GENERAL DISCUSSION}

The results of our experiments lend support to our original hypotheses that articulatory suppression would affect phonological recoding in reading and that some of the effects previously found were influenced by the phonological recoding process.

The stress effect found by Drewnowski and Healy (1982) was again confirmed in three-syllable words, but was at best only marginally significant in two-syllable words. Articulatory suppression significantly reduced this effect in the third syllable of three-syllable words, although not in the second syllable of two-syllable words; this suggests the possibility that phonological recoding is the locus for the stress effect in three-syllable words, but may not be the locus for the marginal effect in two-syllable words. Articulatory suppression had no facilitative effect on either "the" or "of." In fact, it appeared to have had the opposite effect in each case, suggesting that errors on these words are not attributable to factors relevant to phonological recoding, such as the atypical pronunciation of any letter (the factor emphasized by Read, 1983). More generally, these findings imply that phonological recoding is not involved in the unitization of reading elements and that the reading units identified by the letter detection task are perceptual visual units, rather than memory or response units.

Although our results are inconsistent with the hypothesis that subjects make a disproportionately large number of detection errors on "the" or "of" because they are scanning a phonologically recoded memory representation of the text for the target letters, these findings cannot rule 
out the contribution of other phonological factors to these letter detection effects. Besner and Davelaar (1982) argued, for example, that there are at least two phonological codes used by readers, one involved in lexical access and the other involved in postlexical memory processes. They demonstrated that articulatory suppression disrupted only the second of these codes (see also Kleiman, 1975). Hence, it remains possible that prelexical phonological processes contribute to the pattern of letter detection errors.

Whether or not prelexical phonological processes are involved in letter detection, it is clear from the present results that the stress effect with three-syllable words is attributable to phonological recoding, because suppression did eliminate that effect. The question arises, then, what is the role of phonological recoding in the detection task? It has been argued (e.g., Baddeley \& Lewis, 1981) that subvocalization, which is prevented by articulatory suppression, may not be necessary when reading for meaning. Nevertheless, subvocalization does seem to be used in many reading situations. Slowiaczek and Clifton (1980) have offered two hypotheses to explain how subvocalization can aid in reading comprehension. According to the memory hypothesis, subvocalization is used to translate the visual input into a phonological code, because the phonological representation lasts longer in working memory. Alternatively, according to the prosodic structure hypothesis, subvocalization is used to form a representation that reveals the prosodic structure of the text, so that subvocalization changes the organization of the memory representation instead of its durability. The present results cannot prove or disprove these two hypotheses. However, the fact that the stress effect was eliminated by suppression is consistent with the notion that stress is encoded in the phonological representation formed by subvocalization; the notion that stress is encoded is crucial to the prosodic structure hypothesis, because stress is an important prosodic feature.

It is important to keep in mind that only one of the letter detection effects studied here was eliminated by articulatory suppression: the effect of syllable stress in threesyllable words when the target letter occurred in the third syllable. This finding suggests that subvocalization or phonological recoding plays a major role in letter detection only at the end of longer words. Other factors, such as unitization, seem to predominate for short words and at the beginning of longer words. This finding is underlined by the fact that Drewnowski and Healy (1982, Experiment 3) did not find an effect of stress on the first syllable of three-syllable words and by the fact that the effect of stress was only marginally significant in the twosyllable words in the present Experiment 1. Phonological recoding may come into play only relatively late in the processing of a given word, after its initial letters and syllables have been identified through visual pattern recognition.

\section{REFERENCES}

BADDELEY, A., \& LEWIS, V. (1981). Inner active processes in reading: The inner voice, the inner ear, and the inner eye. In A. M. Lesgold \& C. A. Perfetti (Eds.), Interactive processes in reading (pp. $107-$ 129). Hillsdale, NJ: Erlbaum.

BesNer, D., \& DavelaAR, E. (1982). Basic processes in reading: Two phonological codes. Canadian Journal of Psychology, 36, 701-711.

Corcoran, D. W. J. (1966). An acoustic factor in letter cancellation. Nature, 210, 658.

Drewnowski, A., \& Healy, A. F. (1982). Phonetic factors in letter detection: A reevaluation. Memory \& Cognition, 10, 145-154.

Estes, W. K. (1973). Phonemic coding and rehearsal in short-term memory for letter strings. Journal of Verbal Learning \& Verbal Behavior, 12, 360-372.

HEALY, A. F. (1975). Coding of temporal-spatial patterns in short-term memory. Journal of Verbal Leaming \& Verbal Behavior, 14, 481-495.

Healy, A. F. (1976). Detection errors on the word the: Evidence for reading units larger than letters. Journal of Experimental Psychology: Human Perception \& Performance, 2, 235-242.

Healy, A. F., \& Drewnowski, A. (1983). Investigating the boundaries of reading units: Letter detection in misspelled words. Journal of Experimental Psychology: Human Perception \& Performance, 9. 413-426.

Healy, A. F., \& NaIRne, J. S. (1985). Short-term memory processes in counting. Cognitive Psychology, 17, 417-444.

KLeIMAN, G. M. (1975). Speech recoding and reading. Journal of Verbal Learning \& Verbal Behavior, 14, 323-339.

KrUeger, L. E. (1970). The effect of acoustic confusability on visual search. The American Journal of Psychology, 83, 389-400.

KuČera, H., \& FranCIS, W. N. (1967). Computational analysis of present-day American English. Providence, RI: Brown University Press.

LABERge, D., \& Samuels, S. J. (1974). Toward a theory of automatic information processing in reading. Cognitive Psychology, 6, 293-323.

LEVY, B. A. (1971). Role of articulation in auditory and visual shortterm memory. Journal of Verbal Learning \& Verbal Behavior, 10, 123-132.

LEVY, B. A. (1978). Speech processes during reading. In A. M. Lesgold, J. W. Pellegrino, S. D. Fokkema, \& R. Glaser (Eds.), Cognitive psychology and instruction. New York: Plenum.

LEvy, B. A. (1983). Proofreading familiar text: Constraints on visual processing. Memory \& Cognition, 11, 1-12.

MCClelland, J. L., \& RumelHart, D. E. (1981). An interactive activation model of context effects in letter perception: Part 1. An account of basic findings. Psychological Review, 88, 375-407.

McCusker, L. X., Hillinger, M. L., \& Bias, R. G. (1981). Phonological recoding and reading. Psychological Bulletin, 89, 217-245.

MurRAY, D. J. (1967). The role of speech responses in short-term memory. Canadian Journal of Psychology, 21, 263-276.

READ, J. D. (1983). Detection of Fs in a single statement: The role of phonetic recoding. Memory \& Cognition, 11, 390-399.

SLowiaCzeK, M. L., \& CLIFToN, C. (1980). Subvocalization and reading for meaning. Journal of Verbal Learning \& Verbal Behavior, 19, 573-582.

TELL, P. M. (1971). Influence of vocalization on short-term memory. Journal of Verbal Learning \& Verbal Behavior, 10, 149-156.

Waters, G. S., Komoda, M. K., \& Arbuckle, T. Y. (1985). The effects of concurrent tasks on reading: Implications for phonological recoding. Journal of Memory \& Language, 24, 27-45.

(Manuscript received December 26, 1984; revision accepted for publication July 29, 1985.) 